\title{
Consulta Coletiva: O Espaço da Mulher
}

\author{
Dulcéa Machado Martins \\ Josinéa Lima do Amaral \\ Marli T. Lisboa Dourado \\ Norma Cali de C. Gomes ****
}

Este trabalho foi desenvolvido no S/CMS "Pindaro de Carvalho Rodrigues", Rio de Janeiro, 1988, por assistente social, nutricionista, enfermeira e médica. Teve como objetivos: melhorar a qualidade de atendimento; discutir os resultados dos exames, $o$ tratamento e a importância do preventivo para a saúde da mulher; propiciar à mulher um fórum de discussōes de suas questôes; contribuir para a reciclagem dos profissionais, através da troca de experiências e de informações.

A metodologia utilizada constou de agendamento para consulta subseqüente; avaliação dos resultados dos exames; estabelecimento da terapêutica; discussão coletiva dos resultados dos exames entre equipe $e$ usuárias; discussão livre sobre temas de interesse das mulheres.

Obtivemos como resultados: o aumento da oferta de consultas de primeira vez em 42,7\%; do tempo de consulta em dez minutos por cliente; da cobertura de exame preventivo e de mamas; rastreamento de sifilis e gonorréia; melhora na qualidade do atendimento à mulher, enquanto ser integral: valorização de suas experiências e vivências, seja na discussão de queixas e problemas, seja na avaliação dos serviços de saúde. A relevância deste trabalho pode ser evidenciada no fato de ser uma experiência pouco comum, podendo servir como ponto de referência para a discussão sobre o aumento da oferta de consultas, aliado à qualidade no atendimento.

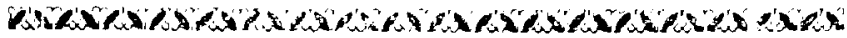

- Mestrado em Serviço Social. Coordenadora de Programas do CMS. VI RA.

** Nutricionista do CMS. VI RA.

*** Enfermeira do PAISMCMS. VI RA.

**** Medica ginecomobstetra. Coordenadora do PAISMI PAISC-CMS. VI RA.

\section{INTRODUÇÃO}

A consulta coletiva em ginecologia - condição a resultado de uma prática comum entre trabalhadores da saúde que ainda acreditam no trabalho coletivo - propiciou-nos, enquanto profissionais, mulheres e cidadẫs, reflexões diversas acerca de questōes relacionadas à condição feminina. 
Colocadas em diferentes momentos do trabalho e do texto, tais questōes apontam para o encontro/desencontro constante vivenciado pelas mulheres em relação às suas experiências, desejos, açōes, sentimentos.

A ambigüidade toma conta de seu cotidiano não porque ela não saiba o que quer, por ser inferior, frágil e menor, segundo a sociedade - mas porque

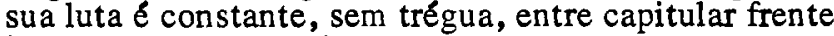
às expectativas, papéis, sentimentos e açōes que reproduzam o modelo tradicional e construir novas formas de ser, pensar, sentir e fazer que apontem para sua condição enquanto mãe, trabalhadora, companheira, cidadă.

E aqui gostaríamos de trazer uma reflexão: a fala das mulheres apontando para a saúde e nảo para a doença, pois năo se trata, apenas, de cuidar do corpo doente, mas de pensar também as demais situaçôes - relação com o companheiro, falta de informaçōes, dificuldade de acesso e deficiências dos serviços de saúde, os sentimentos - enquanto dificuldades que limitam sua saúde e impedem sua realização plena.

Acreditamos que a experiência da consulta coletiva tenha contribuído para este processo de valorização da mulher nos serviços de saúde - seja ela profissional ou usuária - ao tentar restituir-lhe, mesmo que precariamente, sua condição de sujeito de sua vida: suas ações, seus pensamentos, seu falar sendo priorizado como forma para não somente ver a mulher mas, também, para que ela seja considerada, efetivamente, participante da discussão e solução de seus problemas e dificuldades.

\section{HISTÓRICO}

A consulta coletiva em ginecologia é uma prática de atenção à saúde da mulher, elaborada por profissionais do Centro Municipal de Saúde Píndaro de Carvalho Rodrigues da VI RA (Região Administrativa) e desenvolvida no período entre abril e setembro de 1988.

O centro de saúde em questão é uma unidade de cuidados primários, situado na Gávea, zona sul da cidade do Rio de Janeiro.

A VI RA é composta por bairros nobres que, em contraste, abrangem também seis favelas e três conjuntos habitacionais.

A população feminina, maior de 15 anos, compreende um universo estimado de cerca de 85 mil mulheres, das quais uma parcela depende exclusivamente dos serviços públicos para o controle de sua saúde.

$O$ planejamento das atividades de implantação do PAISM, em 1988, foi elaborado a partir da avaliação 
dos dados produzidos pelo setor, no ano de 1987 , onde encontramos:

a. Cobertura: $5,48 \%$ da meta estabelecida pela Secretaria Municipal de Saúde (30\% da população com mais de 15 anos).

b. Produtividade: $31 \%$.

c. Capacidade ociosa: $69 \%$.

A nível de práticas educativas, foi constatada a existência de um grupo informativo para gestantes, desenvolvido pela então enfermeira do setor. Inexistia uma rotina mínima para o atendimento da cliente.

Verificou-se que, se fosse alcançada uma produtividade de $100 \%$, considerável parcela da população-alvo permaneceria, ainda, desassistida. conizava:

Desta forma, o planejamento das atividades pre-

- atendimento de boa qualidade;

- oferta que pudesse atender às necessidades da demanda espontânea;

- redução dos índices de absenteísmo;

- desenvolvimento de práticas educativas, procurando garantir um espaço onde as questōes das mulheres pudessem ter uma abordagem integral.

A padronização feita pelo Conselho Regional de Medicina do Rio de Janeiro de 12 consultas, por médico, por turno de quatro horas, veio reduzir a oferta de consultas em $25 \%$ e aumentar o tempo disponível para cada cliente em $33,3 \%$. No entanto, este aumento de tempo é ainda insuficiente, se forem levadas em consideração a coleta criteriosa dos dados do Prontuário da Mulher (S. M. S., RJ) e a consulta propriamente dita, onde o profissional deve ver a mulher como um ser integral - ouvindo suas queixas, valorizando suas experiências, percebendo suas dificuldades -, realizar o exame clínico-ginecológico, colher material para citologia oncótica (preventivo) e para rastreamento de gonorréia, discutir as dúvidas, solicitar outros exames complementares, orientar e medicar.

Aumentar mais o tempo de consulta implicava maior repressão de demanda.

Verificou-se que havia a possibilidade de um só profissional, em um único turno, atender um grupo grande de mulheres (25 a 30$)$, para a entrega dos resultados dos exames realizados na primeira consulta. Este espaço poderia propiciar a implantação de um trabalho de grupo, informal, onde as orientações poderiam ser dadas coletivamente. Desta forma, os demais profissionais estariam com disponibilidade para atender um maior número de clientes de primeira vez, com aumento no tempo de consulta. A tabela I evidencia a diferença entre as alternativas possiveis. 


\section{TABELA I}

Distribuição da Oferta de Serviços (1) Segundo Diferentes Critérios (OMS, Cremerj, Consulta Coletiva)

\begin{tabular}{l|c|c|c}
\hline Oferta de Servigos & OMS & Cremerj & Cons,Col.(2) \\
\hline N: Cons,/MEdicos/Turno & 16 & 12 & 8 a 30 \\
Oferta-Cons, & & & \\
MGdicos/MEs & 272 & 204 & 224 \\
1: Vez & 136 & 102 & 104 \\
Subsequiente & 136 & 102 & 120 \\
\hline
\end{tabular}

Fonte: PAISM/CMS - VI RA

(1) Dados calculados de acordo $\infty \mathrm{m}$ a duraçåo média de consulta/cliente:

- OMS : 15mim.

- Cremerj : $20 \mathrm{~min}$.

- Consulta Coletiva : $30 \mathrm{~min}$.

(2) Média de turnos/médico ao mes: 17, sendo 13 turnos mensais com 8 atendimentos de 1: vez; 4 turnos mensais com 30 atendimentos subsequientes (consulta coletiva).

\section{OBJETIVOS}

- Melhorar a qualidade de atendimento em função do aumento do tempo disponível para cada consulta, sem prejuízo da oferta.

- Discutir os resultados dos exames, tratamentos indicados e a importância do preventivo para a saúde da mulher.

- Propiciar à população feminina um fórum de discussão de suas questổes.

- Promover trocas de experiências e de informaçōes - equipe multiprofissional e clientela -, possibilitando a reciclagem constante dos profissionais.

\section{DESENVOLVIMENTO DO TRABALHO}

\section{Metodologia}

Implantação da rotina no atendimento da clientela da ginecologia (ver CMS, 1989). 
Consideramos esta etapa como parte da metodologia da consulta coletiva, porque garantiu a uniformidade de açōes necessárias a um exame considerado completo.

Preparo: Atividadés que antecedem a consulta coletiva (anexo 1).

\section{Consulta Coletiva}

- Apresentação dos profissionais da equipe de coordenação.

- Distribuição dos resultados dos exames com as receitas em anexo.

- Elucidação quanto à proposta do trabalho.

- Esclarecimentos sobre as patologias detectadas no grupo, o tratamento instituldo, o uso do creme vaginal, o tratamento simultâneo do parceiro, a transmissibilidade de algumas doenças, a importância do exame periódico, a importância do exame das mamas, os termos técnicos que aparecem nos laudos.

- Debate a partir das questốes colocadas pelo grupo: o espaço da mulher.

- Avaliação das mulheres sobre esta nova experiência, a nível de atençāo à saúde.

\section{Recursos Humanos}

Para implementação do trabalho com grupos de mulheres, contamos com uma equipe composta dos seguintes profissionais: assistente social, enfermeiro, médico, nutricionista, psicólogo.

\section{Recursos Materiais}

- Documentação do CMS-Ficha Central.

- Prontuário da Mulher - PAISM/SMS, Rio.

- Resultados dos exames solicitados.

- Medicamentos previstos para o programa.

- Outros: folhetos, cartazes, material demonstrativo dos métodos contraceptivos.

Registro

Optou-se pela anotação do conteúdo das reuniōes, simultaneamente à realização das mesmas, respeitando as expressōes próprias às mulheres.

\section{RESULTADOS}

\section{Dados Gerais}

Entre abril e setembro, foram realizadas 16 consultas coletivas, atendendo em média 23 clientes por consulta. 
Percebemos um aumento percentual de $42,7 \%$ no número de consultas de primeira vez de ginecologia, quando comparado com igual perfodo do ano anterior. A abrangência da consulta coletiva atendeu a $34 \%$ das consultas de primeira vez.

Em relação ao resultado dos exames citológicos, pudemos observar que a grande maioria das mulheres era portadora de processos inflamatórios diversos.

\section{TABELA II}

Distribuição das Patologias Ginecológicas Segundo Diagnóstico Laboratorial (Exames Colpocitológicos) S/CMS VI RA - Abril/Set/1988

\begin{tabular}{lcr}
\hline Diagnóstico & Freqũência & $\%$ \\
\hline Negativo & 08 & 1,3 \\
Inflamatório & 609 & 96,6 \\
Displasias & 12 & 1,9 \\
CA Invasivo & 01 & 0,2 \\
\hline Total & 630 & 100,0 \\
\hline
\end{tabular}

Fonte: PAISM/CMS VI RA(*)

(*) A diferença entre o número de mulheres que participaram da consulta coletiva (368) e o de resultados de exame (630) deve-se, em parte, ao grande atraso na entrega dos mesmos; assim, as usuárias sem resultado de exame não ficavam para o grupo $e$, muitas vezes, năo retornavam após o segundo agendamento.

Dentre os agentes infecciosos mais comuns, apontam-se, em ordem decrescente: flora bacteriana mista, trichomonas vaginalis, gardnerella e candida albicans.

Nas displasias, houve predominância de infecção por virus do grupo papova.

Quanto ås DST, a patologia mais comum foi a infecção por chlamydia.

A terapêutica instituída para estas patologias foi a preconizada pelo Manual do Ministério da Saúde.

\section{Discussão Coletiva dos Exames}

Ao apresentar os resultados dos exames às mulheres, procurava-se elucidar os termos técnicos e as pato- 
logias mais comuns detectadas no grupo, atraves de uma rápida explanação, em linguagem simples. Deixava-se o grupo levantar outras dúvidas:

- O que é avaliação cito-hormonal prejudicada?

- O que significa flora bacteriana exuberante?

- Flora bacteriana é grave? entre elas:

Outras informações, também, eram solicitadas,

- Essas doenças que a senhora colocou no quadro são as mais perigosas?

- Vem cá, esses vermes que a senhora colocou no quadro tiram o desejo sexual da mulher?

- O que é isso aqui? (Referindo-se a flora de Doederlein.)

- Doederlein? Esse é bom?

Simultaneamente, eram apresentados os tratamentos, a forma de sua utilizaçấo (individual/casal) e a importância de completá-los. As dúvidas e discussões apontaram para a forma de utilização, sobretudo do creme vaginal, limitaçōes à vida sexual. Neste momento estimulava-se a participação das mulheres na troca de experiências.

- Eu coloco na hora de dormir, para segurar.

- A pomada faz ficar toda melada.

- Meu marido não deixou eu usar o creme. Ele diz que só faz uma vez por semana e não vai ficar sem. Ele tem um nivel cultural inferior ao meu.

Ele acha um absurdo usar creme. Ele acha que estou corneando ele.

É preciso parar e pensar.

A mulher sente o problema. Procura sozinha, como parte do casal, o serviço de saúde - com todas as suas limitações de organização, reflexo das políticas de saúde (fila, falta $ı$ de medicamento, falta de profissional e outros) -, submete-se a exames médicos e laboratoriais e, ao buscar o resultado, recebe orientação para o seu tratamento e, muitas vezes, para o tratamento do seu parceiro.

Cabe a ela, além de perceber os sinais, tratar a doença que lhe acomete, convencer o parceiro a fazer o mesmo, situaçäo que muitas vezes the traz aborrecimento, desgaste, infelicidade.

- o Dr. mandou meu marido tomar remédio e a gente brigou porque ele não queria tomar. Al, a gente se separou. Ele morou dois meses na casa da mãe. Quando ele voltou, o médico mandou uma carta

Cadernos de Saúde Pública, RJ, 7 (2): 267-283, abr/jun, 1991 
para ele comparecer ao consultório. Pessoa ignorante é fogo... Ele disse que a doença era minha e não dele. Depois que ele tomou o remédio, nunca mais tive nada. Isso é machismo.

- Nenhum homem gosta de se tratar e nem tomar remédio.

- A gente tem que conversar com o marido e convencer.

$E$, no entanto, a mulher sabe que a sua saúde depende de um novo modo de agir do homem - deseja o seu efetivo companheirismo e sua solidariedade -, sua ação enquanto ser integral.

- Para isso meu marido é muito compreensivo.

- O homem é o parceiro da gente; por isso ele precisa se tratar também.

Exame Ginecologico: A mulher se expōe

A mulher tem como obrigação cuidar do seu corpo.

- Eu gosto de fazer (o preventivo) de seis em seis meses.

- Eu faço de dois em dois anos.

- Eu me cuido muito.

- Eu acho importante a gente saber como está por dentro.

Todavia, quem conhece (conhece?) o seu corpo ou quem sabe como a gente estå por dentro é o médico.

Evidencia-se aqui a mulher reproduzindo o discurso médico - a ele cabe explorar o que se passa dentro de cada uma -, desvalorizando seu conhecimento, negando suas experiências, excluindo-a da participação e do controle sobre seu corpo.

O sentimento feminino mais explicitado é o da vergonha, limitando o conhecimento do seu corpo, evidenciando/reforçando a dominaçăo, preconceitos e tabus.

A passividade aprendida se transforma em submissão, gerando desconfiança e medo.

- Eu de primeiro ficava tão nervosa quando ia fazer o preventivo, sentia tão nervosa...

- A gente sente vergonha de muitas coisas.

- Muitas vezes a gente tem vergonha de ficar nua na frente do médico.

Dentro deste quadro, a mulher percebe-se fragmentada: de um lado, utiliza-se da vergonha como forma de se "proteger" da exposição no exame e, por outro, reconhece a inevitabilidade dele. 
- Acho que a gente tem que ter vergonha. É a primeira vez que a gente vai mostrar o corpo para uma pessoa que a gente não conhece.

- Eu acho que a gente náo tem que ter vergonha. Um dia, a gente vai ter que abrir as pernas mesmo.

Conversa livre

Os depoimentos das mulheres retratavam várias questōes a respeito das suas vivências, no seu cotidiano. Para facilitar a discussão destes depoimentos, decidimos agrupá-los de acordo com as prioridades colocadas pelas próprias mulheres.

Assim, destacamos como temas: as questōes da contracepção; da sexualidade feminina - tendo como contraponto subjacente a questão da relação entre o homem e a mulher - e dos serviços de saúde.

\section{A mulher $e$ a contracepção}

A predominância deste tema na fala da mulher pode ser pensada enquanto "dever" que lhe cabe no controle do número de filhos.

Poucas falas relatam, do ponto de vista individual, experiências positivas neste aspecto.

- Eu coloquei o DIU e achei ótimo.

- Eu tomo comprimido há 11 anos e não sinto nada.

- Eu acho legal ligar as trompas, porque não tive saúde na minha gravidez.

Este depoimento relacionando a gravidez à doença imediatamente articula contracepção à saúde, reproduzindo o discurso médico e social das atuais polf́ticas de saúde do Brasil.

A predominância aparece nas experiências negativas das mulheres, ou porque o método utilizado não foi eficiente, ou porque lhe causa danos à saúde.

- Quando eu tomo anticoncepcional, eu fico sem tesão.

- Eu tomo anticoncepcional há quatro anos. Eu era magrinha e agora estou gorda.

- A tabela não resolveu. (A mulher mostra o filho no colo).

- Eu tinha mais medo de esquecer de tomar do que de rezar.

- DIU só dá doença pra mulher.

Neste aspecto, uma fala nos chama a atenção para experiências agressivas que determinados métodos impōem à mulher. 
- Esse nogócio de tomar ptlula todo o dia não dá certo. Eu ia colocar o DIU, mas eu ouvi tanta coisa sobre ele, al não coloquei. (Esta mulher tinha o Norplant implantado no membro superior há quatro anos).

Além disso, podemos pensar na opção (ou falta de opção?) da mulher por métodos radicais, na tentativa de dar uma solução definitiva à via crucis da gravidez. Por um lado, um pouco de sossego não faz mal, pode até possibilitar o espaço para o prazer. Por outro lado, pode evitar o desgaste e o cansaço, na utilização dos serviços de saúde que tanto deixam a desejar.

- Eu preferi ligar logo.

- O bem que o DIU faz é que não deixa a gente engravidar.

Evidenciam-se nos depoimentos, a falta de informação e as dúvidas a respeito dos métodos contraceptivos existentes e/ou utilizados.

- Que dia se começa a tomar a pllula?

- Tomando pllula sem parar faz algum mal?

- Mas usando camisinha dá o mesmo prazer?

- Dra., este também evita? (falando do creme vaginal).

- Essa borracha fica desse jeito? (falando do diafragma).

- A vagina fica muito aberta. Como a gente vai tirar?

- Mesmo tomando anti-concepcional pode engravidar? Mesmo esquecendo um ou dois dias?

- Conheço uma mulher que só tomava quando ia transar. At ela prenhou.

A "responsabilidade" imputada à mulher em relação à contracepção coloca o peso do mundo sobre seus ombros, se considerarmos a manipulação existente em relaçāo à reprodução (Berquó, 1985): se ela quiser informar-se sobre os métodos contraceptivos, tendo em vista a presença de sua saúde, onde poderá ela ir? Pode ela contar com serviços públicos que trabalhem a regulação de sua fertilidade, garantindo sua saúde? Sua experiência, seus desejos serão considerados por aqueles "que sabem" ou terá ela que se submeter a esse saber - dono de seu corpo, de sua vida?

\section{A Mulher e a sexualidade}

A mulher como ser integral evidencia-se, de maneira muito forte, quando a conversa aponta, também, 
para sua sexualidade, indicando as questōes da sua relação com o sexo masculino. Aqui o que se revela é que ela não é apenas um órgão sexual ou de reprodução, doente ou sadio, mostrando-se por inteiro, através de suas vivências e preocupações. Evidencia-se, também, a ocupação do espaço de discussão e de reflexão, por parte dessas mulheres, no sentido de construção (conscientização) da condição feminina - enquanto ser integral e sujeito de suas açōes (principalmente nas ações/políticas de saúde).

- Tem seis anos que eu não sinto nada com o meu marido. Parei de ter orgasmo. Antes de casar eu sentia muita coisa, depois acabou. Eu sempre minto para ele dizendo que estou cansada. Sempre tive vergonha de falar sobre isso com ele.

Uma das questões da condição feminina relaciona-se à repressão de seus desejos, de suas necessidades...

- Eu tenho vontade, mas sou muito parada.

- Para mim, antes, uma só não era suficiente. Agora que estou mais velha, me contento quando tenho vontade. Estou sem há 12 anos.

- Tenho vontade, mas não sinto nada. Antes era quente, agora tá ficando frio.

Em todos os grupos de mulheres, as discussões resvalam para a relação com o seu companheiro e/ou suas experiências de vida conjugal, mostrando desânimo, falta de diálogo, solidão (ver Luz, 1982).

- Fiquei oito anos sem arranjar homem; as mulheres não acreditam. Sempre fui bonitinha para arranjar homens. Arrarjjei um que é mulherengo e muito charmoso. Não quero morar com homem. Eu vou ficar seis meses sem ter nada com ele. Ele diz que mulher não pocle botar banca com ele. Ele arranjou uma mulher que é conterrânea minha.

- Eu fui casada 35 anos. Sempre disse para ele que o dia que arranjasse outra eu botava ele para fora de casa. Uma mulher ligou para ele e marcou um encontro. Eu escutei pela extensão. Reuni todos os filhos e disse que o casamento tinha acabado. Coloquei ele para fora. Meus filhos me apoiaram. Eu vivi para ele como uma empregada e ele nunca reconheceu. A gente sofre muito, afinal são 35 anos. Não quero mais arrumar homem. Quando eu tiver pegando fogo, chamo o bombeiro. Acho que agora não tem mais graça. 
- Meu marido chega em casa e grita muito. Quando tento conversar com ele, só sai briga. Ele diz que eu gosto de outro. Ele é muito quadradão. Ele não aceita que o problema é dele.

A oportunidade de se ver como ser "normal" aconteceu numa situação onde as mulheres trocavam e pensavam coletivamente suas vivências.

- Eu fui educada que quando a gente tem a primeira relaçâo sexual tem que sangrar. Só que eu não sangrei. $O$ meu marido diz que menti para ele. Será que sou normal? (Aqui as mulheres presentes relataram suas experiências neste sentido). ...foi bom eu fazer essa pergunta, porque assim descobri que outras mulheres também nâo sangraram. Isto significa que eu sou normal.

O peso da educação reprimida, da expectativa da sociedade em relação à mulher, aparece na seguinte fala:

- A gente é criada muito certinha. A mulher nunca pode nada.

Apesar de tantos desencontros entre a nulher e o homem, ela ainda acredita que é possível o diálogo, a troca, mesmo entre pessoas diferentes, qua ido diz:

- Eu gostaria que os companheiros da gen e estivessem aqui.

Ou seja, ocupando e usufruindo de um espaço onde a troca exista, também, com eles, como companheiros e cúmplices.

A visão da mulher sobre o serviço de saúde

A mulher, ser integral, है vista como tal pelo serviço de saúde? As queixas, explicitamente colocadas para o profissional, poderiam ser melhor esclarecidas se esta mulher fosse ouvida para além cessa queixa? Se ouvirmos o que ela nos diz?

$O$ acesso ao local de prestação do serviço e aos recursos, que se supõe que tal serviço ofereça, é revelado como dificil.

- Sábado estava chovendo e eu sangrava muito. Liguei para a farmácia e ele me deu uns comprimidos marrons. Não tinha dinheiro para pegar um táxi e ir ao hospital. Os remédios são muito caros. Os médicos não sabem os remédios que a farmácia possui.

Observa-se, também, o não-empenho da mulher na busca do tratamento. 
- Eu também não usei o remédio que a doutora mandou eu usar. Eu não achei e também não me esforcei para procurar.

O seu não-esforço pode estar relacionado à sua descrença no atendimento recebido?

Alguns dos depoimentos colocaram na ordem do dia a questão da qualidade dos serviços de saúde:

- Sinto dores na mama, parece um troço que está enraizado. Já operei duas vezes. Quando faço exame fora, o médico me olha toda, aqui não.

- O doutor passou a pomada e eu continuo do mesmo jeito, eu continuo com coceira.

- Eu comprei uma revista chamada "Minha" que explica por que a mulher quando tem relação doi.

A "dominação" do saber técnico sobre o conhecimento/sentimento que a mulher possa ter do seu corpo $\varepsilon$ revelada por alguns depoimentos:

- Quem estuda medicina conhece mais o corpo do que qualquer pessoa.

- Eu acho importante saber como a gente está por dentro.

- Quem sabe como a gente tá por dentro é o médico.

O depoimento abaixo expressa com veemência o distanciamento entre o profissional e a mulher:

- Minha mãe sempre disse pra eu ir ao médico, pegar o remédio e não perguntar nada porque eu poderia atrapalhar o médico. Quanto menos eu souber, melhor.

\section{CONSIDERAÇÕES FINAIS} a mulher?

Ao procurar uma unidade de saúde, o que busca

Seria acaso a busca da cura de seus males físicos, rotulados pelo profissional como doença? Seria o desejo de expor as suas questōes enquanto ser integral, ou o sintoma específico por ela demonstrado apenas facilitaria o acesso? Poderia ser o desejo de ser ouvida?

Observa-se que a procura da unidade de cuidados à saúde tem se dado, basicamente, em fases cíclicas e específicas da vida da mulher, fases com as quais, de alguma forma, ela já sabe como lidar: gravidez, puerpério, preventivo.

Esta fragmentação, de certa maneira, facilita 0 distanciamento cliente/profissional. Propicia ao profissional uma atuação puramente técnica, com condutas estanques e previsíveis para cada momento, e contribui 
para fortalecer a "escuta viciada" para a qual foi academicamente formado.

Pensou-se que, ao aumentar o tempo da consulta, haveria maior disponibilidade do profissional para o atendimento de cada cliente para, desta forma, reverter esta relação.

Ao verificar-se a concretização deste objetivo, pode-se supor que a relação médico/paciente tenha se dado de forma mais integral.

Retornando para apanhar o resultado, a mulher defronta-se com um grupo de clientes reunidas para o mesmo fim. Ela já não encontra mais o médico que a atendeu na primeira vez. Ao invés dele, depara-se com uma equipe multiprofissional, desconhecida, que a convida a participar de uma prática que lhe é totalmente estranha.

Que impacto esta prática pode produzir?

- Frustração - por não ter encontrado o mesmo profissional para o qual se expôs e conseguiu se colocar?

- Medo - de ter mais uma vez, que passar por experiências desconhecidas?

- Vergonha - ao achar que sua intimidade seria devassada publicamente?

- Ansiedade - de participar de uma nova vivência?

- Raiva - por não ter ao seu alcance, mais uma vez, a palavra amiga antes encontrada?

$A$ avaliação dos depoimentos das mulheres não apontaram para estes sentimentos.

Apesar de nem todas terem externado suas opiniöes, o momento da consulta coletiva parece ter propiciado um espaço para a mulher colocar questōes que a pudessem levar à reflexão de situaçōes vivenciadas em seu cotidiano.

A socialização do conhecimento aumenta as expectativas da clientela e o nível de exigência em relação ao atendimento no serviço de saúde, o que vem colaborar com o profissional para o repensar de suas práticas.

Apesar de havermos nos defrontado com inúmeras dificuldades, como atraso nos resultados dos exames citológicos, falta de medicamento, espaço físico inadequado, entre outras, acreditamos que conseguimos avançar dentro da proposta de melhor qualidade no atendimento da mulher, propiciando:

- aumento no tempo de consulta;

- melhor cobertura de exames preventivos;

- melhor cobertura de exames de mamas;

- rastreamento de sífilis e gonorréia;

- acesso de um maior número de clientes ao atendimento ginecológico. 
A partir das trocas de experiências, na consulta coletiva, a mulher passa a ter uma abordagem enquanto ser integral.

Cabe ressaltar, ainda, dois pontos que julgamos da maior relevância:

A postura dos profissionais que participaram da consulta coletiva, quando do atendimento individual, sofre transformaçōes importantes, redundando em maior abertura na relação com a cliente.

A importância de não transformar os trabalhos de grupo em locais exclusivos da qualidade do atendimento. Em outras palavras: é evidente a necessidade de socializar as discussōes ali travadas, para o conjunto de profissionais da Unidade, objetivando contribuir para a sua reciclagem.

\section{Anexo 1}

PREPARO: Atividades que antecedem a consulta coletiva

A. Auxiliar de Enfermagem:

- Retirar de véspera as fichas do arquivo central.

- Anexar o prontuário * da mulher à ficha central*.

- Anexar os resultados de exames (no mínimo a citologia, bacterioscopia e o DRL ao prontuário correspondente).

Cadernos de Saúde Pública, RJ, 7 (2): 267-283, abr/jun, 1991

(*) Instrumentos utilizados na rede básica do S.MS. Município do Rio de Janeiro. 
(*) Esta atividade foi também desenvolvida por um enfermeiro (a), devidamente treinado (a), de acordo com a normatizaçáo do Ministério da Safide.
B. Médico **

- Fazer a análise do prontuário.

- Correlacionar os achados com os exames laboratoriais.

- Avaliar a medicação prescrita inicialmente e estabelecer a terapêutica complementar para cada caso.

- Instituir o tratamento inicial para aquelas que não tenham sido tratadas.

- Confeccionar as receitas.

- Transcrever para a ficha central os resultados dos exames, assim como a prescrição feita e a referência para outros serviços, quando houver.

- Notificar as DST detectadas.

- Fazer levantamento das patologias detectadas no grupo agendado.

- Selecionar (listar) os casos que necessitem atendimento individual (imediatamente após a consulta coletiva):
a. Displasias.
h. Neoplasias.
e. DST.
d. Inflamatórios por vírus (HPV e Herpes).

\section{AGRADECIMENTOS}

Este trabalho não teria sido possível sem a importante colaboração de diversos companheiros do CMS VI RA, aos quais as autoras agradecem.

- Dr. Harvey Ribeiro de Souza Filho, Diretor do CMS, pelo apoio, incentivo e discussão sobre 0 trabalho.

- Diana do Prado Valladares.

- Rosali Finkielsztejn.

- Maria Lúcia Santos e Amara Príncipe, da Equipe de Enfermagem do PAISM-CMS.VI RA.

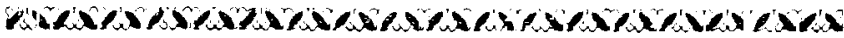

This experience took place in a Medical Center, in Rio de Janeiro, in 1988. The group responsible for it included a social worker, a nutritionist, a nurse and a gynecologist.

The aims were: to offer better health care; to discuss the importance, the results and the appropriate 
therapies of the Pap smear; to offer women an opportunity to meet and discuss their problems, experiences, desires, expectations; and to offer to the health professionals the opportunity to re-think their own practices.

The methodology used was characterized by making appointments for a medical exam subsequent to a Pap smear; evaluation of each Pap smear result and its appropriate treatment, previous to the group consultation; group discussion about the Pap smear results; and about themes brought up by women clients. The main results were: an increase of $42.7 \%$ in the number of nomen who went for their first medical exam; an increase of ten minutes in the length of each medical exam; better screening for syphilis and gonorrhea, better quality of health care within the perspective of women as integral boings (greater appreciation of a woman's own experiences, be it in terms of her complaints and problems be it in her evaluation of the medical care system).

This kind of consultation is of rather recent date and if it becomes more wide-spread it could result in an increase in the number and quality of the medical exam.

\section{REFERÊNCIAS BIBLIOGRÁFICAS}

BERQUÓ, Elza. “O Plano de Ação Mundial de Populaçăo e - Planejamento Familiar no Brasil". In: Folha de Säo Paulo, 13/01/85, Folhetim. Pp. 6-7.

BORGES, Sherrine M. N.; ATIÊ, Eliana. "Vida do Mulher: estratégias de sobrevivência no cotidiano". In: COST A, Nilson do Rosário et alii (org.). Demandas Populares, Polfticas Pübli cas e Salide. Colkxão Saúde e Realidade Brasileira, Vol. II. Movimentos Sociajs e Cidadania. Petrópolis, Vozes/Abrasco, 1989. Pp. 165-184.

CASTRO, Ana Maria M. de; BRANDÄO, Elaine Reis; CARNEIRO, Fernanda. Saíde da Mulher: Salvaçäo da Vida. Coleção Saúde \& Educação, Vol. 2. Petrópolis, CDDH/Cepel, 1990.

LUZ, Madel Therezinha. "O lar e a maternidade: instituiçōes políticas". In: LUZ, Madel T. (org.), O Lugar da Mulher: estudos sobre a condição feminina na sociedade atual. Rio de Janeiro, Ed. Graal, 1982. Pp. 9-31.

XA VIER, Dulcinéia; §́ VILA, Maria Bethânia; CORREA, Sonia. "Questōes feministas para a ordem médica: o feminismo e o conceito de saúde integral". In: LABRA, Maria Eliana (org.), Mulher, saude e sociedade no Brasil. Coleção Saude e Realidade Brasileira. Petrópolis, Vozes/Abrasco, 1989. Pp. 203-222.

CMS, VI RA. "O Minhocäo - Relato de uma experiência". Documento elaborado pela equipe de saúde do Centro Municipal de Saúde "Pindaro de Carvalho Rodrigues" - VI. RA. Rio de Janeiro, agosto/1989. Mimeo.

Cadernos de Saúde Pública, RJ, 7 (2): 267-283, abr/jun, 1991 